Article

\title{
Condensation Control to Cope with Occupancy Activity and Effectively Mitigate Condensation in Unheated Spaces by Real-Time Sensor Control Strategy
}

\author{
June Hae Lee and Myoung Souk Yeo * \\ Department of Architecture and Architectural Engineering, Seoul National University, Seoul 08826, Korea; \\ juneleeh8@snu.ac.kr \\ * Correspondence: Correspondence: msyeo@snu.ac.kr; Tel.: +82-2-880-7353
}

Received: 2 April 2020; Accepted: 12 May 2020; Published: 14 May 2020

check for updates

\begin{abstract}
The occurrence of condensation and its prevention strategies are already known phenomena in physical buildings. However, the condensation problem still exists in newly constructed buildings. In the typical Korean residential unit, the balcony space is the most problematic area for condensation. This paper provides a solution for preventing condensation by considering a change from the fixed parameters of buildings to an IoT (Internet of Things) implemented real-time sensor control solution. To provide this solution, field measurements are acquired for a building diagnosis, an EnergyPlus simulation and site experiment to investigate the new parameters. The field measurements reveal that occupancy activity increases the possibility of condensation, and the control strategy involves the application of insulation, the use of ventilation, and controlling the opening of the balcony door. The insulation thickness and ventilation rate parameters are reviewed by the simulation; however, the uncertainty related to the moisture generation rate by occupants makes it difficult to ascertain the building's physical parameters. Door and intermittent ventilation is controlled by the real-time sensor IoT experiment to block the moisture transfer and remove the moisture generation. This experiment has been confirmed to shorten the remaining time of condensation. Instead of providing a fixed parameter values for solution, applying sensor-controlled strategy is effective for uncertain cases involves with moisture generation. This study provides a control solution for condensation in vulnerable spaces and simultaneously provides a new design approach that adopts IoT applications to control the indoor conditions.
\end{abstract}

Keywords: condensation; Korean residential balcony; fixed parameter; occupancy parameter; Internet of Things (IoT)

\section{Introduction}

Condensation inside a building, which indicates inadequate indoor air quality, contributes to the deterioration of materials. The accumulation of moisture on the surfaces of materials allows biological activities to occur [1,2], causing degradation and increasing maintenance costs during the building lifecycle. Exposure to molds can cause severe human health issues such as respiratory illnesses, asthma, and allergies [3-5]. Childhood asthma cases are especially related to condensation inside the home [6,7]. Therefore, it is essential to keep residential buildings free of condensation. For several decades, researchers have studied built environments to determine the causes of condensation; the resulting prevention methods include increasing thermal resistance and using air ventilation strategies [8-14]. Existing guidelines, including the ISO (International Organization for Standardization) and ASHRAE (American Society of Heating, Refrigerating and Air-Conditioning Engineers) standards, are based on 
research related to the thermal and humidity conditions of buildings and enable condensation-free building design to be achieved.

Although we now possess in-depth knowledge regarding the mechanism of condensation and methods for preventing condensation, moisture problems exist, even in newly built environments. In Korea, approximately 14\% of new residential buildings constructed during 2010-2015 were reported to have condensation defects, making condensation the most common defect after noise and malfunctions according to data obtained from the "Defect Review Dispute Resolution Committee" under the Ministry of Land, Infrastructure and Transport in Korea [15]. The most problematic location that suffers from condensation defects in newly built residential units is the balcony area, which is an unheated space in the private unit. Based on our field research of a newly constructed apartment, $30 \%$ of all units reported that the balcony area experienced the most serious condensation. Moon et al. [16] surveyed 466 apartment units with numerous mold complaints and found that $90 \%$ of all units reported the balcony to be the primary area in which mold develops. Thus, balcony spaces are repeatedly built, resulting in condensation problems.

The typical Korean balcony is the product of the occupant lifestyle and real estate situation in Korea. A balcony is generally defined as "a platform projecting from the wall of a building and enclosed by a parapet or railing [17]". However, as shown in the floor plans in Figure 1, a Korean balcony is developed as a part of the residential unit and is enclosed by a concrete wall with a thickness of $200 \mathrm{~mm}$ containing a window; this type of balcony has become conventional for space use and economy consideration. In Korea, balconies are projected outward from the residential unit, allowing residents to view outside, and are considered to be a connection between the outdoor and indoor spaces. Since the early 1990s, the installation of glass windows in balconies has been decreed to reduce noise from the outdoor environment and thermally insulate heated spaces [18]. Given these internal and external partitions, residents often use the balcony as a laundry area and an auxiliary kitchen without a vent system and employ the storage space as a pantry rather than as a relaxation area with an outside view [19]. Additionally, in Korea, the balcony space is considered an additional service area because the balcony is not counted directly as part of the net floor area of the entire unit: only half of the balcony floor area is counted [20]. Therefore, the Korean balcony space is fully equipped in terms of functionality but is not considered to be a part of the living space; hence, it is constructed without any thermal insulation in the walls or a heating system.

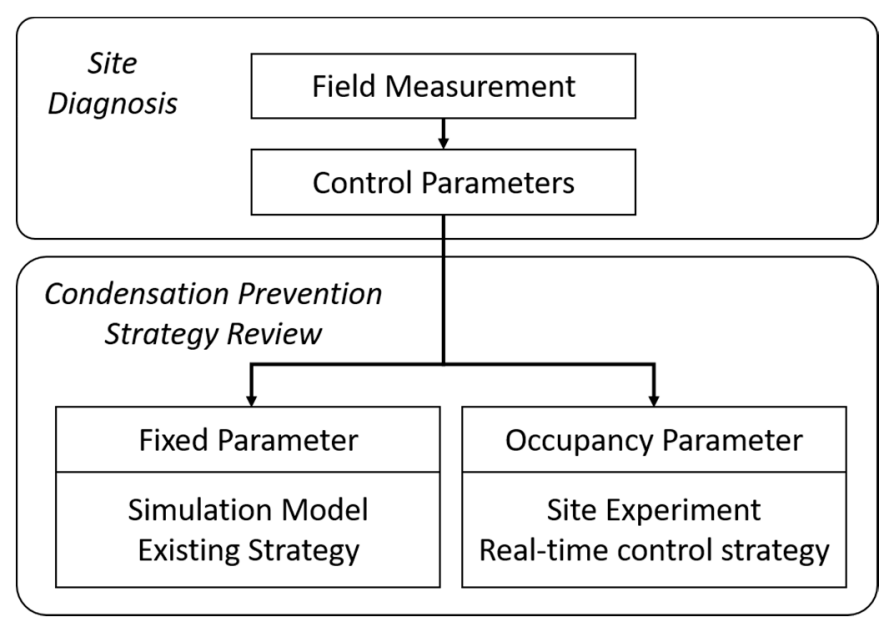

Figure 1. Overview of the work process.

Previous studies diagnosed the cause of condensation in unheated spaces under conditions similar to those of Korean balconies and developed corresponding control strategies. For example, Gutt [21] investigated the attic space, where condensation is caused by moisture transported by an airflow rather than by diffusion through the ceiling structure; the author suggested sealing openings and 
cracks to control the airflow through the attic. Janssens and Hens [22] investigated air leakage as a significant cause of condensation in lightweight roof systems in cold climates and insisted that it is necessary to improve building codes to achieve an adequate air barrier system; however, controlling air leakage is an uncertain practice in construction, which suggests the addition of insulation panels over the air barrier layer. Ali et al. [23] investigated condensation issues in unconditioned spaces adjacent to air-conditioned cooling spaces in tropical climates and researched various types and thicknesses of insulation to increase the thermal resistance of adjacent walls. Moon et al. [24] conducted a hygrothermal simulation to analyze the risk of mold growth on the walls of balcony spaces in Korean apartment buildings; accordingly, they suggested appropriate ventilation rates and restricted moisture production activities to minimize the risk of mold growth.

Existing condensation prevention strategies for unheated spaces are as follows: applying a vapor barrier to reduce infiltration, insulating to increase thermal resistance, and ventilating to remove moisture and restrict moisture production. These methodologies are well-known solutions that have been implemented for many years. However, all previous studies claim that it is important to consider the possibility of design failure due to uncertainties during construction and building use; it is therefore important to consider changes in the boundary conditions, such as indoor humidity rates. ASHRAE standard 160-2009 (Criteria for Moisture-Control Design Analysis in Buildings) provides the criteria for predicting the indoor moisture conditions to implement an appropriate design, such as an HVAC (heating, ventilation, and air conditioning) load, and to remove indoor moisture [25]. However, TenWolde and Walker [26] insist that the data on the generation of moisture are often insufficient to apply a full statistical and practical treatment, causing the design to fail. To gather local data, that is, data not relevant to the abovementioned standard, which is based on the Western lifestyle, Yik et al. [27] investigated the moisture generation rates of Chinese residential buildings in Hong Kong and reported variations in the moisture generation rate according to the different behaviors of people within the same household. Furthermore, Zemitis et al. [28] measured the moisture rates in relation to human respiration and house plant emissions in a climate chamber and measured moisture generation in houses by drying clothes; they asserted that the measured moisture generation rate is less than the ASHRAE standard value.

Sensor technologies provide possibilities for coping with and remedying building uncertainties by collecting measured data. In particular, the IoT (Internet of Things) is developing rapidly due to the proliferation of wireless sensor networks [29]. The IoT makes it possible to analyze massive amounts of data and to control the environment. Recently, the threshold for constructing ubiquitous sensors was lowered to establish an IoT concept of the measuring environment, which enabled the researchers to customize their own device. Moreno et al. [30] presented a building automation platform to monitor energy consumption based on occupant behavior. Bashir and Gill [31] demonstrated a control strategy for oxygen pumps, fire alarms, and lights with virtual sensors using Python code, which can be implemented in real oxygen pumps and fire alarms in the future. Pocero et al. [32] presented an IoT metering device for school buildings and applied an open-source IoT infrastructure to develop a low-cost IoT solution for monitoring energy consumption in indoor environments. Tang et al. [33] presented a smart home lighting system with the ability to leverage sunlight to conserve electricity; the system was developed and evaluated using an Arduino-controlled luminaire with a Raspberry Pi main board controller.

This paper contributes to solving the balcony condensation problem in residential buildings. Although previous studies have provided strong knowledge regarding the occurrence of condensation and prevention strategies, built environments continue to encounter problems with condensation. It is therefore necessary to prevent condensation by not only considering temperature fluctuations but also addressing excess humidity caused by occupants. The influence of humidity on the Korean balcony will be investigated with an existing strategy to derive a fixed parameter for prevention. A dynamic range of humidity rates due to different occupancy behaviors is suggested to apply the IoT strategy to control the occupancy parameters. 


\section{Methodology}

We first diagnose the phenomenon of condensation, which has been repeatedly diagnosed in Korean residential balcony spaces, to derive the parameters for the proposed prevention strategy. The parameters obtained from field measurements are evaluated through a simulation model and on-site experiment, as shown in Figure 1. The author-defined prevention parameters are categorized into two groups: Fixed parameters and occupancy parameters. Fixed parameters are parameters determined after a building is completed by design; these parameters, such as the thickness of insulation, are provided for existing solutions. Occupancy parameters are determined by occupancy behaviors, such as controlling the parameters in response to the indoor conditions. The occupancy parameters are ascertained by the real-time sensor control strategy. The simulation model was reviewed to show the limitations of the existing strategy compared to the real-time sensor control strategy. The site experiment implemented with the IoT concept was reviewed as a confirmed design solution for real-time sensor control strategy.

\subsection{Field Measurement Setup for On-Site Diagnosis}

The investigation was conducted on a north-facing balcony during a period of heating. Almost every Korean apartment unit is designed with two balcony spaces, namely, a north-facing balcony connected to the kitchen and a south-facing balcony connected to the master bedroom, as shown in the floor plan in Figure 2. Compared with south-facing balconies, north-facing balconies are more influenced by kitchen activities and less influenced by solar radiation. Radial floor heating is a conventional feature in Korean residences, and each apartment is individually heated, except for the balcony area. During the experiment, the temperature of the indoor living space, including the kitchen area, was set to $25^{\circ} \mathrm{C}$, while the outdoor average temperature was approximately $4{ }^{\circ} \mathrm{C}$.

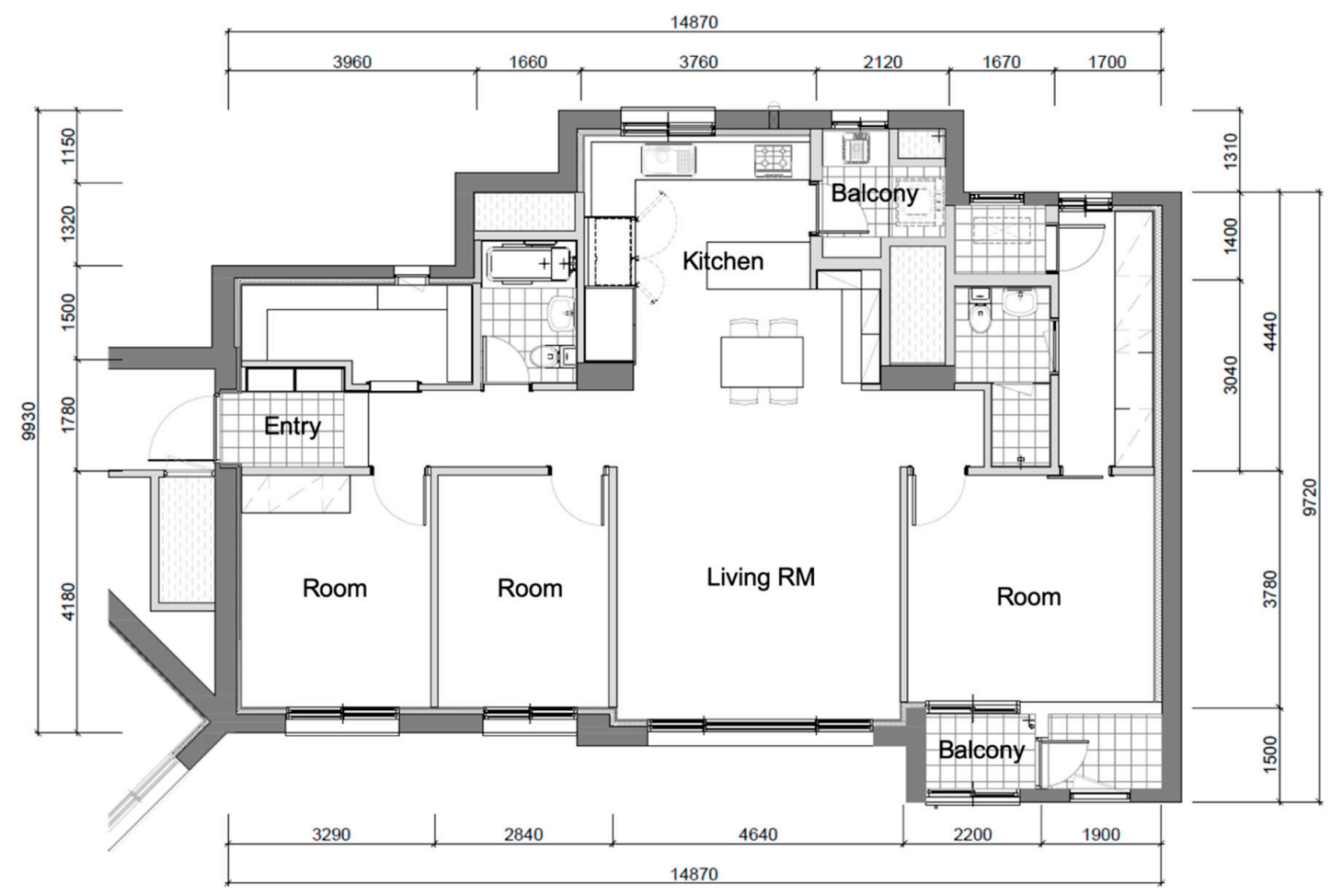

Figure 2. Floor plan of the field experiment unit in Incheon, Korea.

Temperature and humidity were measured every $60 \mathrm{~s}$ during the investigation; the information of the sensors employed in the experiment and the accuracy of the measuring instruments are shown in Table 1. The layout of the measuring points is shown in Figure 3. Surface temperatures were measured 
on the window surface, the north-facing wall, the corner joint of the north wall, and the wall surface adjacent to the outer door. Condensation was determined by the dewpoint temperature, which was calculated from the measured temperature and humidity in the balcony space and then compared with the measured temperature on the lowest surface. In this section, we diagnose the influence of moisture when either the neighboring space or the balcony space is used for the production of moisture. To diagnose the influence of the occupancy behavior in a vacant unit, a portable gas stove was used to boil water in the kitchen, while the humidifier was located in the balcony space.

Table 1. Measurement instrument information.

\begin{tabular}{|c|c|c|c|c|}
\hline \multirow{2}{*}{ Measure Element } & \multicolumn{2}{|c|}{ Field Measurement Instrument } & \multicolumn{2}{|c|}{ IoT Experiment Instrument } \\
\hline & Main Unit & Sensor & Main Unit & Sensor \\
\hline Zone Air & $\begin{array}{l}\text { Data Logger Model } \\
\text { SK-L200THIIa }\end{array}$ & $\begin{array}{l}\text { SK-LTHIIa- } 2 \mathrm{w} / \text { Sensor cord } \\
\text { Temp: } \pm 0.5^{\circ} \mathrm{C} \text { at } 15.0^{\circ} \mathrm{C} \text { to } \\
\quad 35.0^{\circ} \mathrm{C} \\
\text { Humidity: } \pm 3 \% \text { rh at } 15.0{ }^{\circ} \mathrm{C} \\
\text { to } 35.0^{\circ} \mathrm{C}(30 \text { to } 90 \% \mathrm{rh})\end{array}$ & \multirow{3}{*}{$\begin{array}{l}\text { Raspberry Pi } 3 \\
\text { Model B }\end{array}$} & $\begin{array}{c}\text { Adafruit Sensirion } \\
\text { SHT } 31-\mathrm{D} \\
\text { Temp: } \pm 0.3^{\circ} \mathrm{C} \text { most uses } \\
\text { Humidity: } \pm 2 \% \text { rh most uses }\end{array}$ \\
\hline \multirow{2}{*}{ Wall Surface } & \multirow{2}{*}{$\begin{array}{l}\text { National } \\
\text { Instrument Device }\end{array}$} & \multirow{2}{*}{$\begin{array}{c}\text { T-type (Copper/Constantan) } \\
\text { Thermocouple }\end{array}$} & & $\begin{array}{c}\text { Thermocouple Amplifier } \\
\text { MAX31856 }\end{array}$ \\
\hline & & & & $\begin{array}{c}\text { T-type (Copper/Constantan) } \\
\text { Thermocouple }\end{array}$ \\
\hline
\end{tabular}

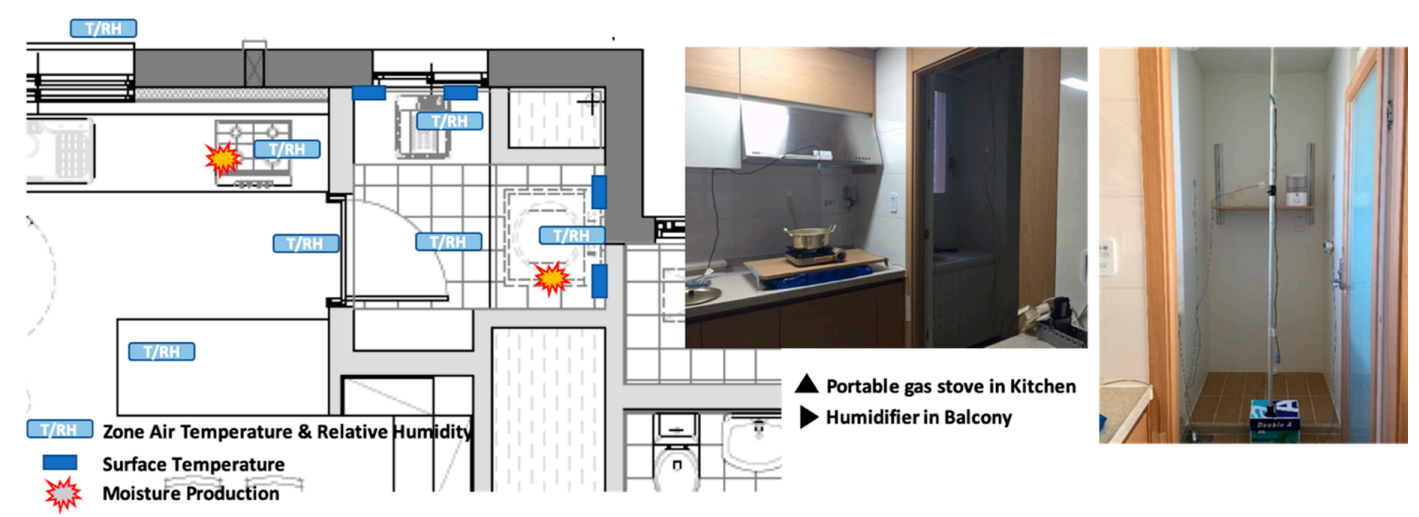

Figure 3. Sensor and moisture generation equipment locations for the site diagnosis.

\subsection{Simulation Model Setup for Parameter Analysis}

The parameters from the on-site diagnosis were evaluated using a simulation model to find an appropriate design value to prevent condensation due to the generation of moisture. We used EnergyPlus ver. 8.6.0 (U.S. Department of Energy, Golden, CO, US) for the simulation model, which was built based on conditions previously obtained through field measurements. The field-measured space was modeled instead of the entire building; the temperatures of the floor and ceiling were assumed to be influenced by the temperatures on the other side of each surface. Furthermore, the balcony and its neighboring spaces (the kitchen, duct space, and plant room) were modeled and connected to allow exchange of energy and mass according to the energy balance and mass balance models in Equations (1) and (2) [34]. In addition, the unheated spaces, such as the duct space and plant room, were modeled to mimic the influence of buffered exterior temperatures on the balcony space. The mass balance model of Equation (2) includes a term reflecting the diffusion of moisture through the wall; however, this term was excluded because the balcony wall of the studied unit is solid concrete, and thus, this term does not affect the simulation of indoor conditions over a seasonal period.

Each room is connected by an airflow network formed by the air pressure difference. In particular, the kitchen and balcony are connected by an airflow network formed by the door opening, which is given in Equation (3) [34]. Air leakage through the wall between the shaft space and plant room is almost nonexistent because the wall constructed between these spaces is concrete, eliminating leakage. 
The value of the discharge coefficient $\left(C_{d}\right)$ in Equation (3), which is the calibrating coefficient, is between the theoretical value and actual measurement: we used Riffat's equation [35], shown in Equation (4), to compute the value of this coefficient. Riffat's equation is applicable to natural ventilation conditions and is based on the temperature difference between two rooms:

$$
\begin{gathered}
F_{i} C_{z, i} \frac{d T_{z, i}}{d t}=\sum_{j=1}^{N_{i, g}} F_{\text {gain }, j} Q_{i, j}+\sum_{j=1}^{N_{i s s u r}} h_{i, j} A_{j}\left(T_{s, j}-T_{z, i}\right)+\sum_{j=1}^{N_{i, A F N}} m_{A F N i, j} C_{p}\left(T_{z, j}-T_{z, i}\right) \\
+\sum_{j=1}^{N_{i, H V A C}} F_{H V A C, j} m_{\text {sup }, i, j} C_{p}\left(T_{\text {supj }-} T_{z, i}\right) \\
F_{i} M_{z, i} \frac{d W_{z, i}}{d t}=\sum_{j=1}^{N_{i, g}} F_{\text {gain }, j} Q_{i, j}+\sum_{j=1}^{N_{i, s u r}} h_{M, j} A_{j}\left(W_{s, j}-W_{z, i}\right)+\sum_{j=1}^{N_{i, A F N}} m_{A F N i, j} C_{p}\left(W_{z, j}-W_{z, i}\right) \\
+\sum_{j=1}^{N_{i, H V C}} F_{H V A C, j} m_{\text {sup }, i, j}\left(W_{\text {supj- }} W_{z, i}\right) \\
m=C_{d} \theta \int_{z=0}^{z=H} \rho v(x) W d z \\
m=C_{d} \theta \int_{z=0}^{z=H} \rho v(x) W d z
\end{gathered}
$$

The simulation model was validated by comparing the field-measured data under the existing nonactive condition and those under the moisture-generation condition. The field-measured data were collected at night (11:00 p.m. to 6:00 a.m. local time), and the simulations agree well with the measured data, as shown in Figure 4. The energy balance simulation refers to the measured result almost same as that shown in Figure 4a. The humidity results show a difference range of $10 \% \mathrm{rh}$ in Figure $4 \mathrm{~b}$. The mass balance simulation model is based on the result of one node fully mixed condition, while the actual humidity changes locally due to local air pressure and air temperature difference. However, the simulation results of humidity changes follow the tendency of the measured results and the difference is within $10 \% \mathrm{rh}$, validating their use in simulation.

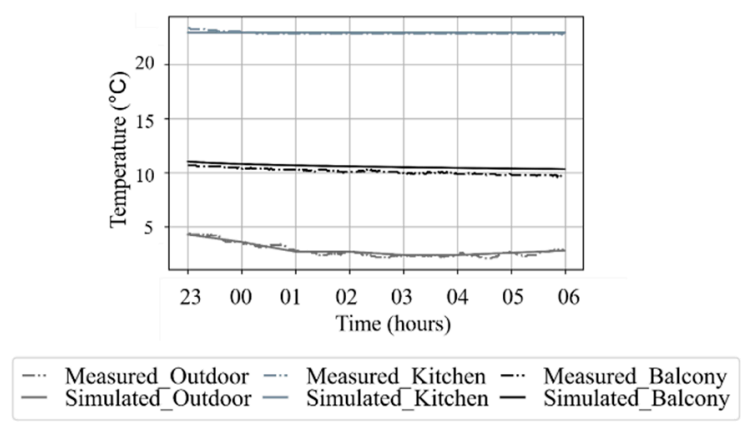

(a)

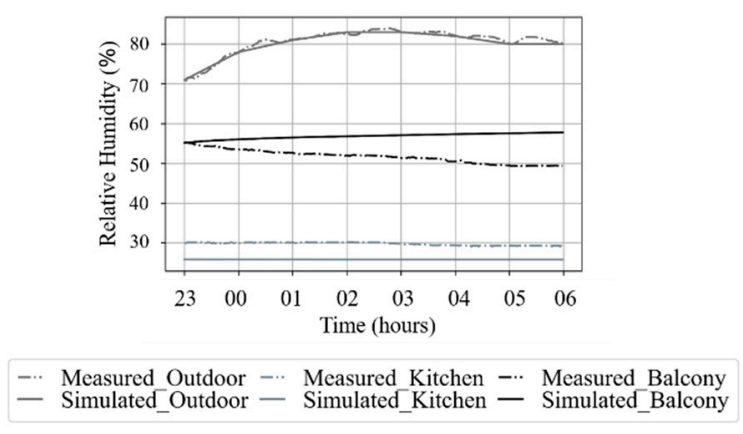

(b)

Figure 4. EnergyPlus model validation: (a) temperature for validating the energy balance model; (b) humidity for validating the mass balance model.

The moisture transfer simulation is validated. Moisture generation was simulated using steam equipment inputs in EnergyPlus, which allows to adjust the ratio of sensible heat and latent heat to provide moisture produce rate. Steam equipment operation in the kitchen zone occurs by the schedule file applied same as the measurement experiment. As shown in Figure 5, moisture is transferred to the balcony space, increasing the absolute humidity inside the balcony space during the times when the door was open. 


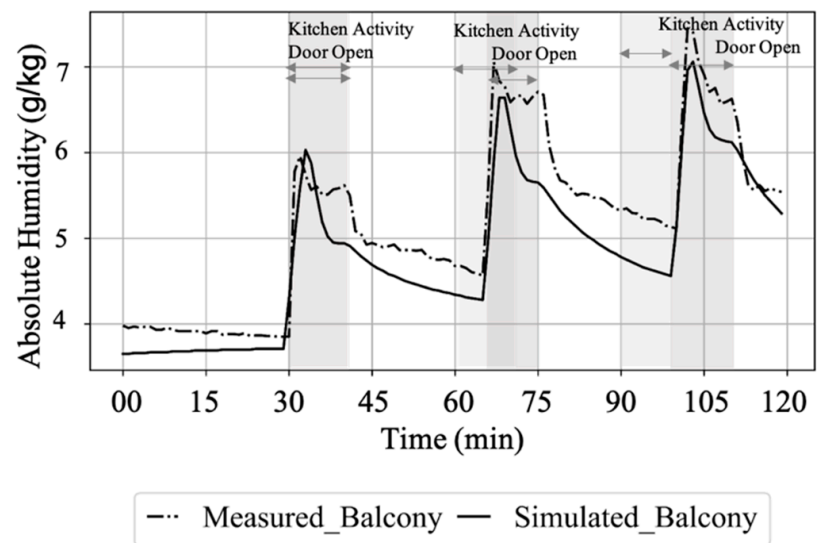

Figure 5. Absolute humidity for validating the moisture transferred by the airflow network.

\subsection{Site Experiment Setup for Parameter Analysis}

Next, the parameters obtained from the on-site diagnosis related to occupancy behaviors were evaluated by an on-site experiment. In the IoT, sensors, actuators, and the Internet framework are used to form a smart environment [29]. In the typical Korean apartment (floor area plan type $84 \mathrm{~m}^{2}$ is national housing, which is standardized by the Korean government) depicted in Figure 6, automated actuators, sensors, and wireless communications were set up to implement the IoT strategy. The information of the sensors employed for this experiment and their accuracy are shown in Table 1. We used a Raspberry Pi 3 Model B as a microprocessor to create our own sensor device and actuators. The actuators were controlled by an on/off relay connected to the Raspberry Pi's GPIO (general-purpose input/output) board. As shown in Figure 7, three microprocessors were used for communicating the data received from the sensors located in different rooms using network socket communications: one sensor was located in the kitchen, while the other two were located on the balcony.

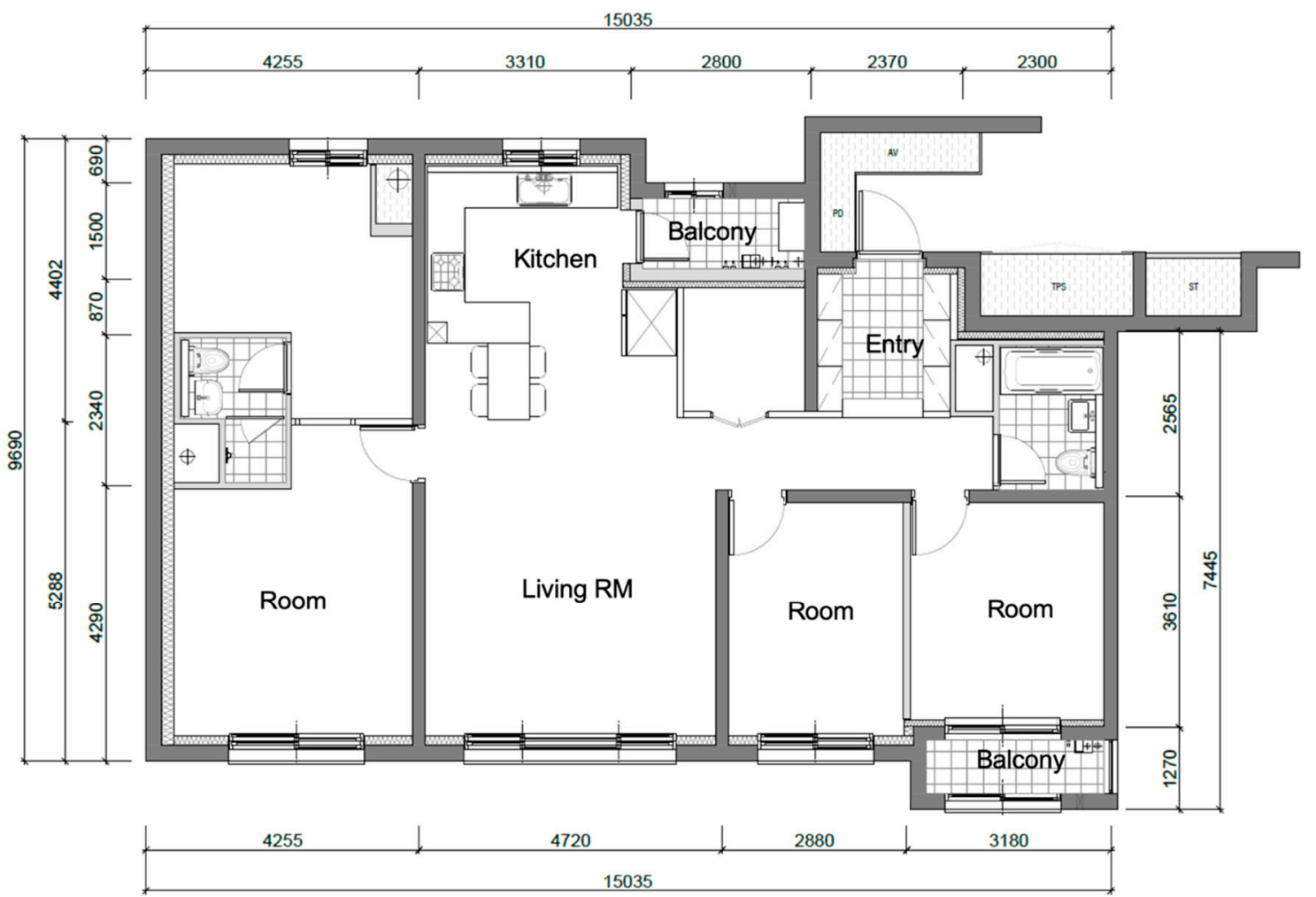

Figure 6. Floor plan of the Site experiment unit in Uljungbu, Korea. 


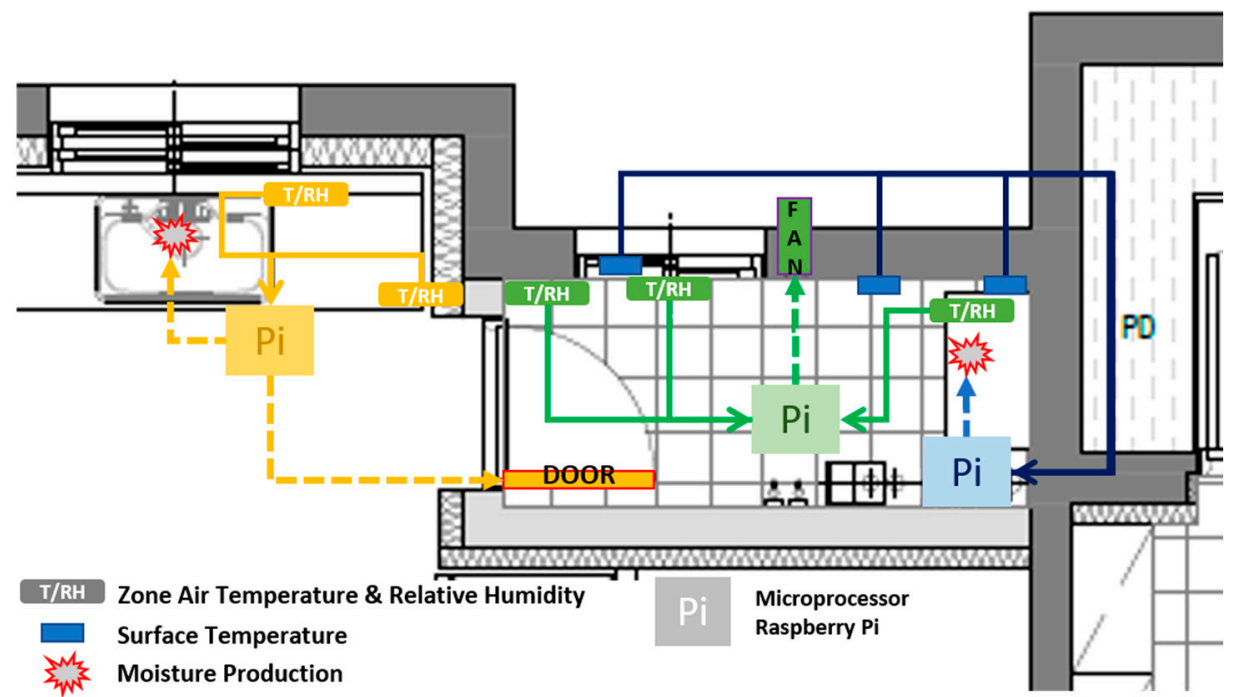

Figure 7. IoT (Internet of Things) experimental setup showing the sensor, actuator, and microprocessor locations.

The experimental control was based on a home Internet gateway, which provided access from different locations anywhere Internet WiFi was available. Unlike the previous field measurements, this experiment was performed remotely using automatic controls. Most of the time, the experimental unit was accessed remotely from a university office located $46 \mathrm{~km}$ from the site. During this assessment, a swing door actuator was installed on the balcony door, and ventilation was provided by installing a constant-airflow of $150 \mathrm{CMH}$ (cubic meters per hour) fan on the balcony ceiling, as shown in Figure 8. To imitate occupancy, the kitchen faucet was connected to a solenoid valve, and the automatic swing door controller on the balcony door was operated to generate and transfer water vapor. Moisture was generated in the balcony area by a humidifier, whose relay on/off operation was controlled by a microprocessor.

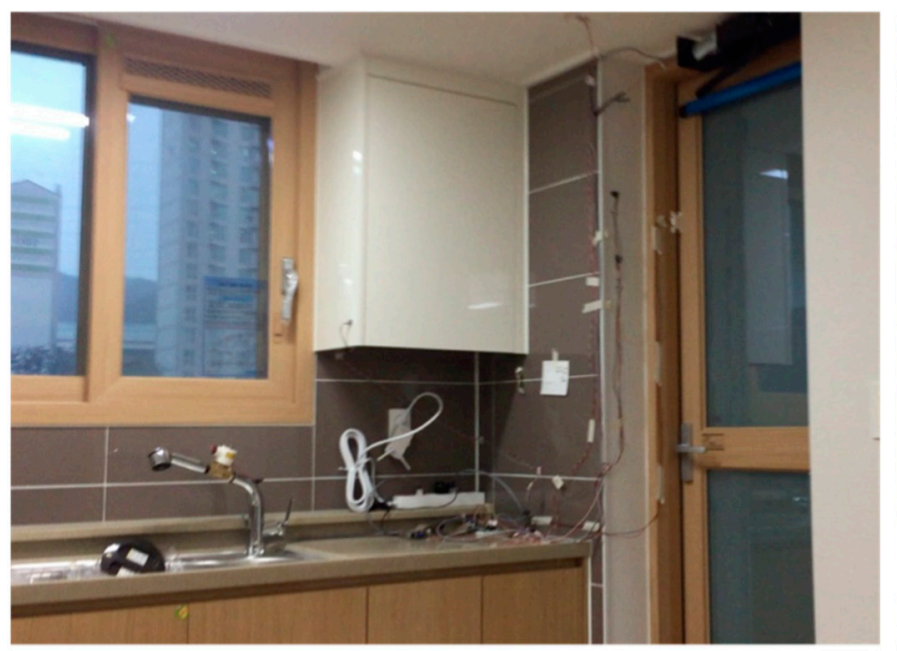

Solenoid valve connected on kitchen faucet Swing door operator installed on balcony door

Ventilation fan attached on balcony ceiling Humidifier located on balcony to imitate moisture production

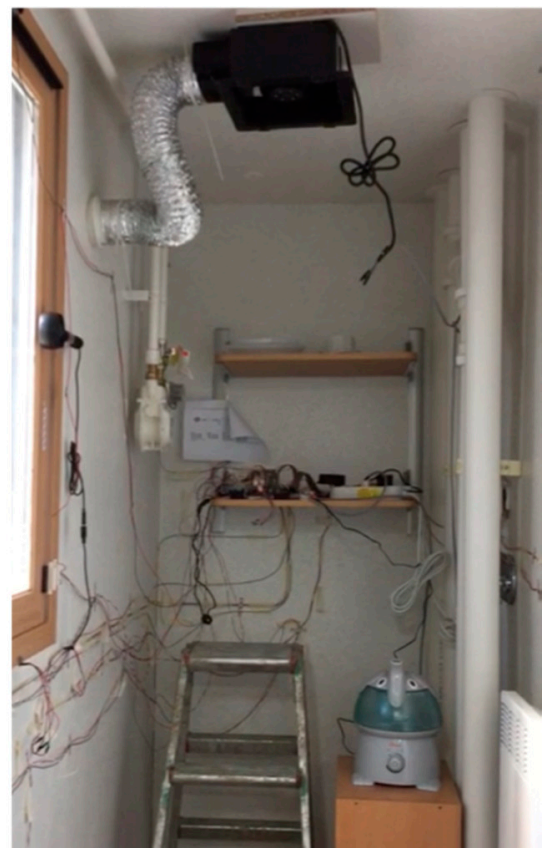

Figure 8. View of the IoT experimental site in the kitchen and balcony. 


\section{Diagnosis of Unheated Spaces to Determine Control Parameters}

Based on a review of the literature on balconies in Korea, architectural features as well as spaces in use are vulnerable to condensation. Moreover, the balcony space is not designed for the prevention of condensation based on occupancy activity. In Figures 9 and 10, the field measured data determined the condensation when the surface temperature value is below the dew point temperature of the nearby sensor. Since the surface is a window and concrete wall with oil paint finish, we neglected the influence of material absorption in determining condensation occurrence. Based on the analysis of the field measurement, the parameters must consider an increase in humidity inside the balcony space to account for reduction in condensation risk:

(1) Keeping the door closed while the neighboring space is being used to generate moisture: A moisture transfer diagnosis experiment was conducted in the balcony space by opening the balcony door at different times while imitating the generation of moisture in the kitchen: the door was closed while the water boiled; the door was opened immediately after the water boiled; the door was opened in the middle of the boiling process; and the door was opened immediately after the heat source for the boiling water was turned off. As shown in Figure 9, condensation was reported whenever the balcony door opened. Condensation was successfully prevented when the door was kept closed while the neighboring space was in use for the generation of moisture.

(2) Applying an insulation panel on the wall adjacent to the outside: Although the balcony air temperature was also influenced by the kitchen temperature when the door was open, an increase in temperature was not sufficient to prevent condensation on the wall surfaces. The temperature of the balcony space was influenced largely by the thermal capacity of the concrete wall; consequently, the temperature quickly returned to the temperature of the space prior to opening the door, as shown in Figure 9a.

(3) Providing ventilation to the balcony space: When the balcony door was open, the RH (relative humidity) immediately increased within three minutes and thereafter dispersed, as shown in Figure $9 \mathrm{~b}$. However, the moisture content in the balcony space increased after several instances of opening the door, as shown in Figure 9c; the balcony is an airtight space, and thus, air does not remove the moisture transferred from the kitchen. As shown in Figure 10, when the window was closed, the generation of moisture in the balcony space increased the RH over $90 \%$. Even when moisture was produced, adequate ventilation, such as opening the window, reduced the condensation risk, as is shown in the case with an open window in Figure 10. 
(a)

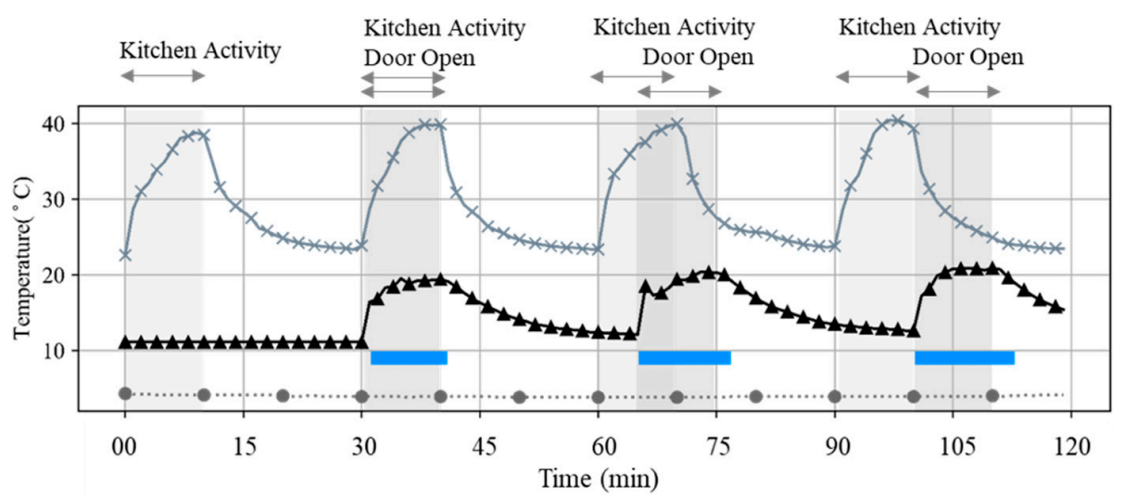

(b)

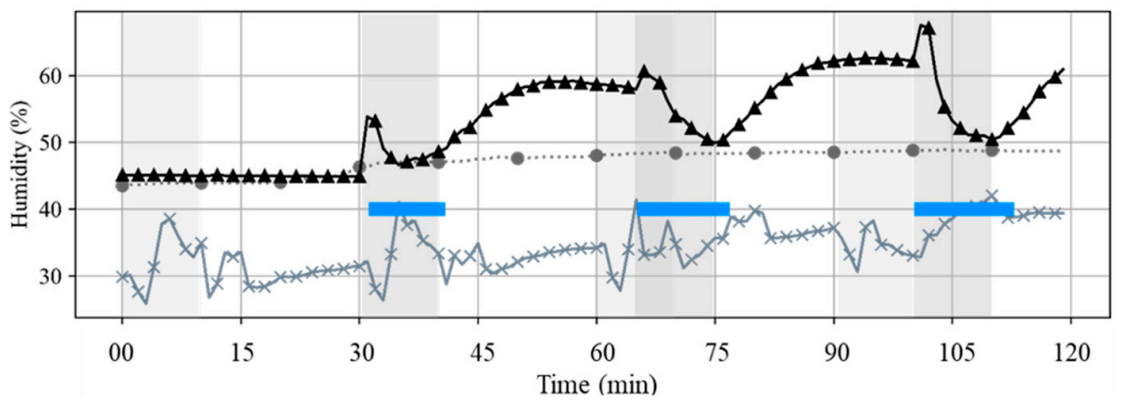

(c)

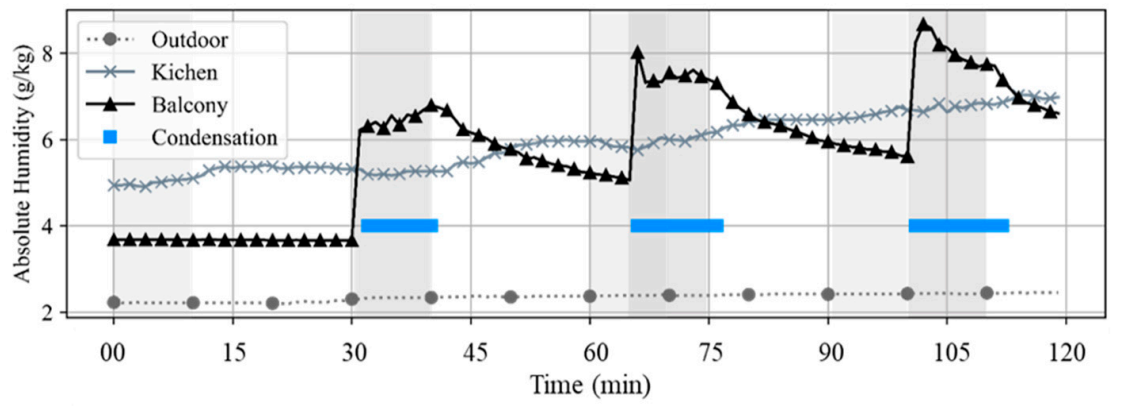

Figure 9. Moisture transfer analysis by field measurements: (a) temperature; (b) humidity; (c) absolute humidity.

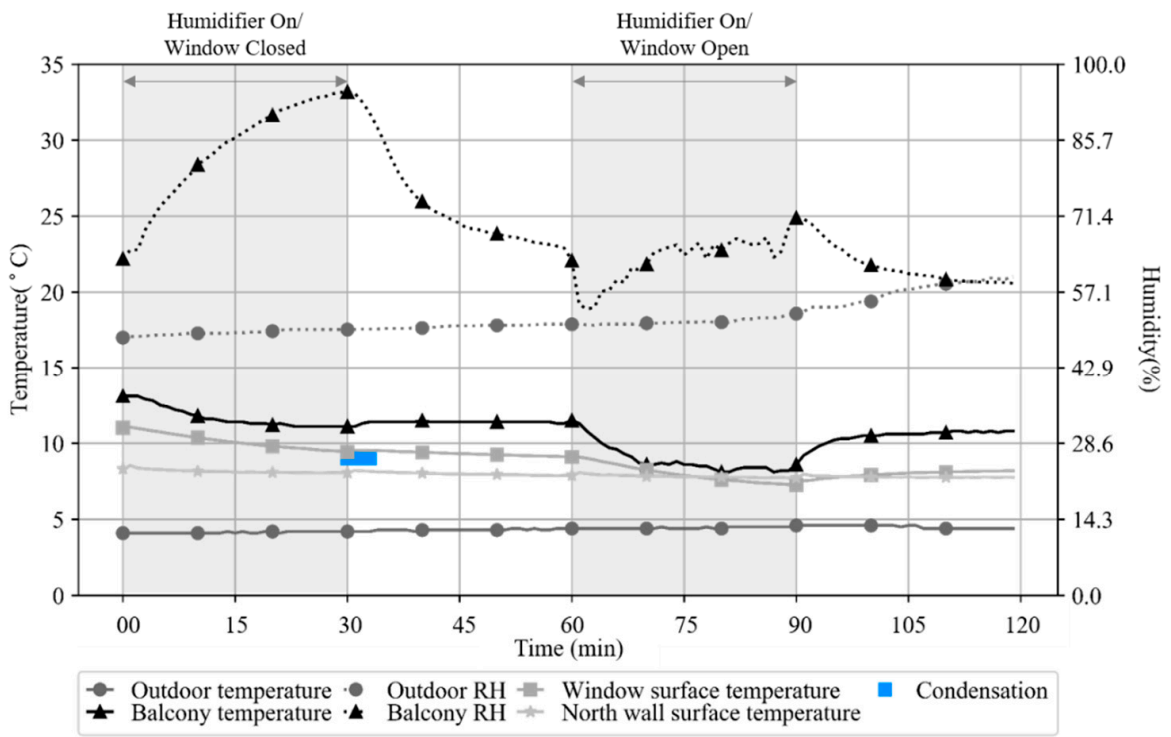

Figure 10. Moisture generation analysis from the field measurements. 


\section{Condensation Control Solution for Unheated Spaces}

\subsection{Fixed Parameter Control by the Existing Strategy}

In this section, the existing strategy, which is to apply insulation panels and employ ventilation, is assessed with respect to humidity produced by occupant activity. The assumed daily moisture generation rate in the simulation was based on the moisture production rate used in the field measurements for the on-site diagnosis. The assessment was conducted during winter (December to February) to ascertain the effectiveness of reduced condensation occurrence times.

The application of insulation panels reduced the influence of the exterior temperature on the wall when applying the same properties of the insulation panel to the conditioned space. As shown in Figure 11, the reduction effect ceased to increase when the insulation thickness exceeded $80 \mathrm{~mm}$. The tested insulation material was a polystyrene insulation panel with a conductivity of $0.032 \mathrm{~W} / \mathrm{mk}$ that is popularly used in Korean buildings; moreover, the indoor air-conditioned spaces at the field measurement site were equipped with this type of insulation with thickness of $85 \mathrm{~mm}$. However, condensation was still observed on window surfaces.

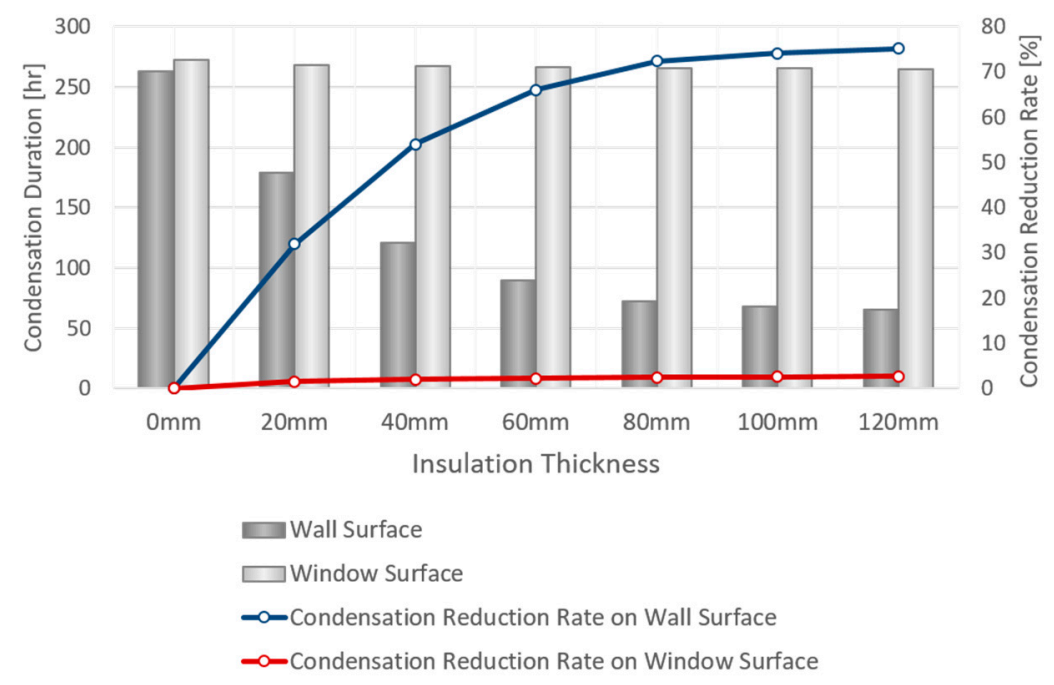

Figure 11. Influence of insulation thickness on condensation duration (in hours) on the north-facing wall surface and window surface during winter and the condensation reduction success rate.

As shown in Figure 12, using a ventilation strategy in the balcony space is effective for both the wall and the window in reducing the duration of condensation. Ventilation rates ranging from $0 \mathrm{CMH}$ to $120 \mathrm{CMH}$ were applied during the evaluation; 90 to $110 \mathrm{CMH}$ is the conventional range of ventilation rates applied to bathrooms in Korean residential buildings. The results reveal that higher ventilation rates may eliminate the condensation risk in the balcony space.

A simulation was also conducted to examine the effectiveness of the proposed condensation prevention method and to investigate the changes in surface temperature due to continuous or intermittent ventilation. Intermittent ventilation was scheduled to begin upon the transfer of moisture. As shown in Figure 13a, the surface temperature dropped when the constant ventilation rate increased, but as shown in Figure 13b, intermittent ventilation did not cause a decrease in the surface temperature. While continuous ventilation uses the outdoor lower temperature to cool down the surface of the balcony wall, intermittent ventilation thermally separates the outdoor space and the balcony. To achieve $90 \%$ comprehensive reduction in condensation by the use of continuous ventilation, a ventilation volume of $60 \mathrm{CMH}$ is the result of simulation for the window and wall, as shown in Figure 13a. With intermittent ventilation, $40 \mathrm{CMH}$ is the result of simulation for both the wall and the window to achieve the same condensation prevention effect, as shown in Figure 13b. 


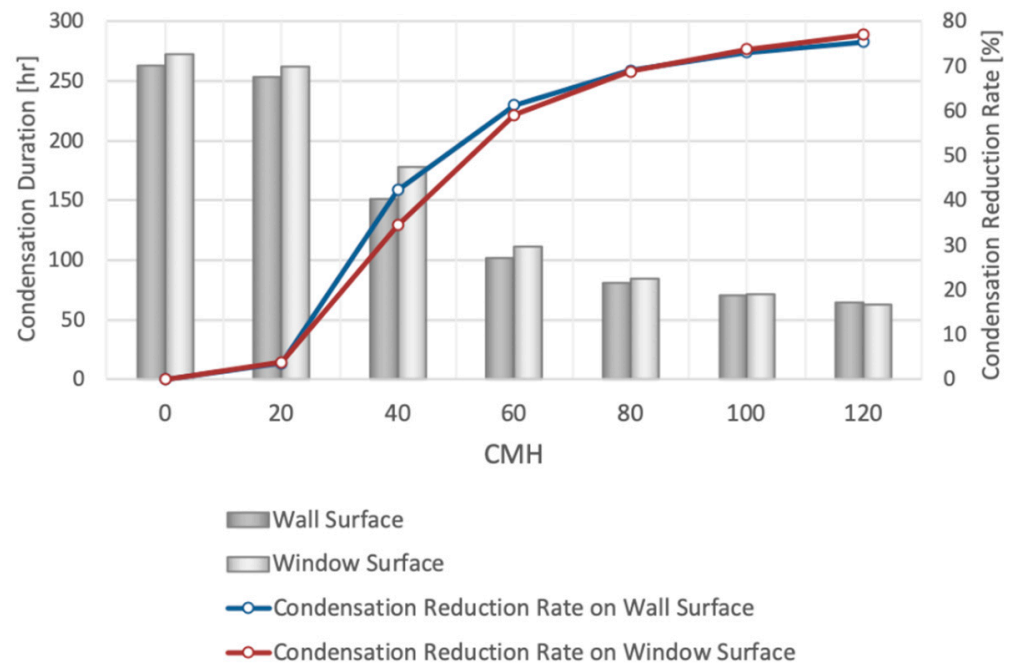

Figure 12. Ventilation rate influence on condensation duration (in hours) on the north-facing wall surface and window surface during winter and the condensation reduction success rate.

(a)

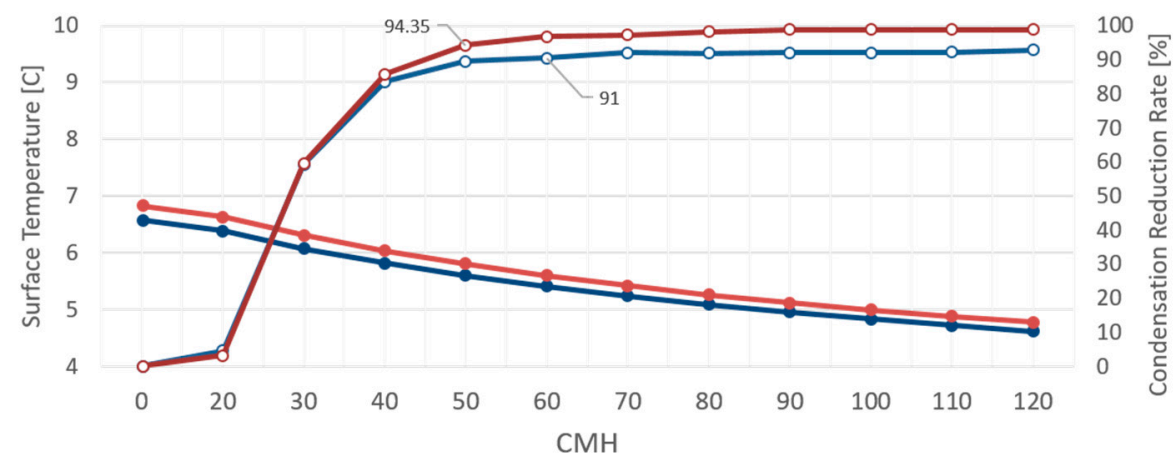

$\multimap$ Wall Surface Temperature

$\multimap$ Window Surface Temperature

$\rightarrow$ Condensation Reduction Rate on Wall Surface

$\rightarrow$ Condensation Reduction Rate on Window Surface

(b)

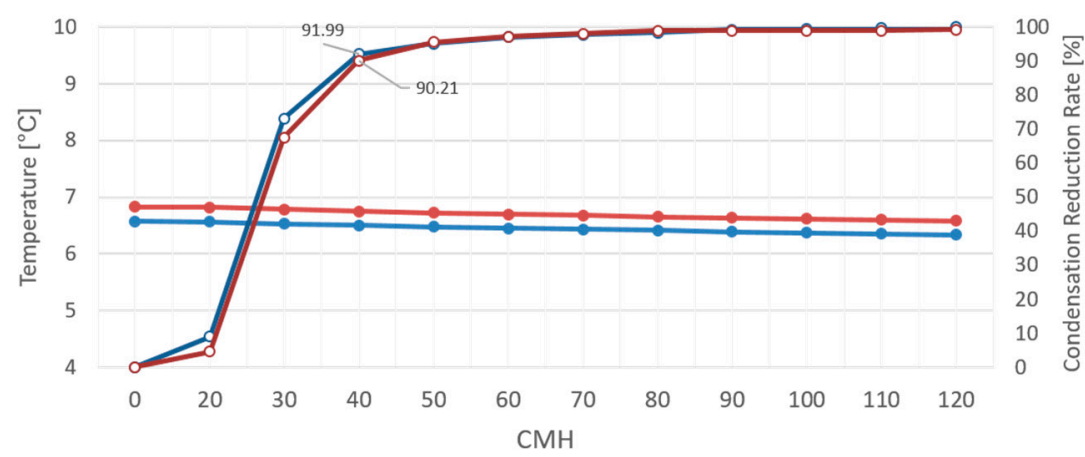

$\rightarrow$ Wall Surface Temperature

$\rightarrow$ Window Surface Temperature

$\infty$ Condensation Reduction Rate on Wall Surface

$-\infty$ Condensation Reduction Rate on Window Surface

Figure 13. North-facing wall surface and window surface temperatures during winter with condensation reduction success rate: (a) constant ventilation; (b) intermittent ventilation 
Designing the balcony space with the determined fixed parameter value will successfully prevent condensation on the balcony. Ventilation is more effective than insulation. In addition, the intermittent ventilation strategy was more effective than continuous ventilation. The assumed daily moisture generation rate in the simulation was based on the moisture production rate used in the field measurement for the on-site diagnosis. This existing condensation prevention strategy involving insulation and ventilation is typically considered during the early design stage to cope with foreseen occupancy conditions. Nevertheless, many unknown factors are related to occupancy that limit the average moisture generation rate; hence, the design parameter may not be reliable or may require further adjustment according to different households and lifestyles. Therefore, the required insulation thickness and ventilation rate vary based on the dynamics of the occupancy pattern.

\subsection{Occupancy Parameter Control by the IoT Strategy}

\subsubsection{Establishing the on-Site Experiment for the Occupancy Parameter}

The condensation control parameter concluded from the field measurements indicates that the balcony door is an effective mechanism for controlling the occurrence of condensation. Additionally, the parameter determined via the simulation shows that intermittent ventilation is more effective than continuous ventilation. The IoT is able to collect data from sensors to determine the situation for implementing this strategy. The concept of the IoT is applied to the on-site experiment, where the mechanism is self-actuated by an algorithm based on reading changes in the environment. Using author-established door and ventilation controls as occupancy parameters, we connected these two parameters by using the microprocessor to actuate those controls based on data received from sensors.

Python is used as the coding language to perform the data collection, condensation calculation, and implement the actuation control algorithm. The programmed control algorithm in the microprocessor compares the surface temperature with the air temperature in the nearby location to determine the occurrence of condensation. When condensation is detected on any of the measured surfaces based on the dew point temperature calculations, a combination of door and fan operations is performed, as shown in Figure 14. The time step for condensation calculation and data collection during the algorithm process is once per minute.

\subsubsection{Results of the Occupancy Parameter Analysis}

The occupancy parameter is properly determined by the real-time sensor data; this parameter easily determines subtle changes in moisture and temperature to decide the duration of the control algorithm. During the experiment, the generation of moisture by occupants was imitated by opening the balcony door and operating a solenoid-controlled faucet in the kitchen. As shown in Figure 15, activity was imitated for $30 \mathrm{~min}$ in the kitchen with the door open, and condensation remained for $112 \mathrm{~min}$ inside the balcony. The balcony door was controlled by a swing door actuator to close based on the sensor detecting the occurrence of condensation. This allows the transfer of moisture from the kitchen to be blocked, thereby reducing the condensation duration by $23 \mathrm{~min}$, as shown in Figure 16 . In addition, the IoT control strategy provides $17 \mathrm{~min}$ of freely keeping the balcony door open since condensation was not been detected at the beginning of occupancy activity.

The proposed IoT strategy overcomes the limitation of the solid parameter solution for preventing balcony condensation. In the existing strategy, once the parameter is determined, it is difficult to change. The on-site IoT experiment with a simple condensation control algorithm provides the potential to address the problem caused by an unpredictable moisture generation rate. We further conducted an experiment involving the generation of moisture within the balcony space to control intermittent ventilation with the IoT strategy. As shown in Figure 17, the ventilation fan operated with the appearance of condensation due to moisture generation inside the balcony, and the ventilation ceased when the production of condensation stopped. This strategy effectively addresses different 
household lifestyles regarding different moisture generation activities, such as loads of laundry or the boiling of soup.

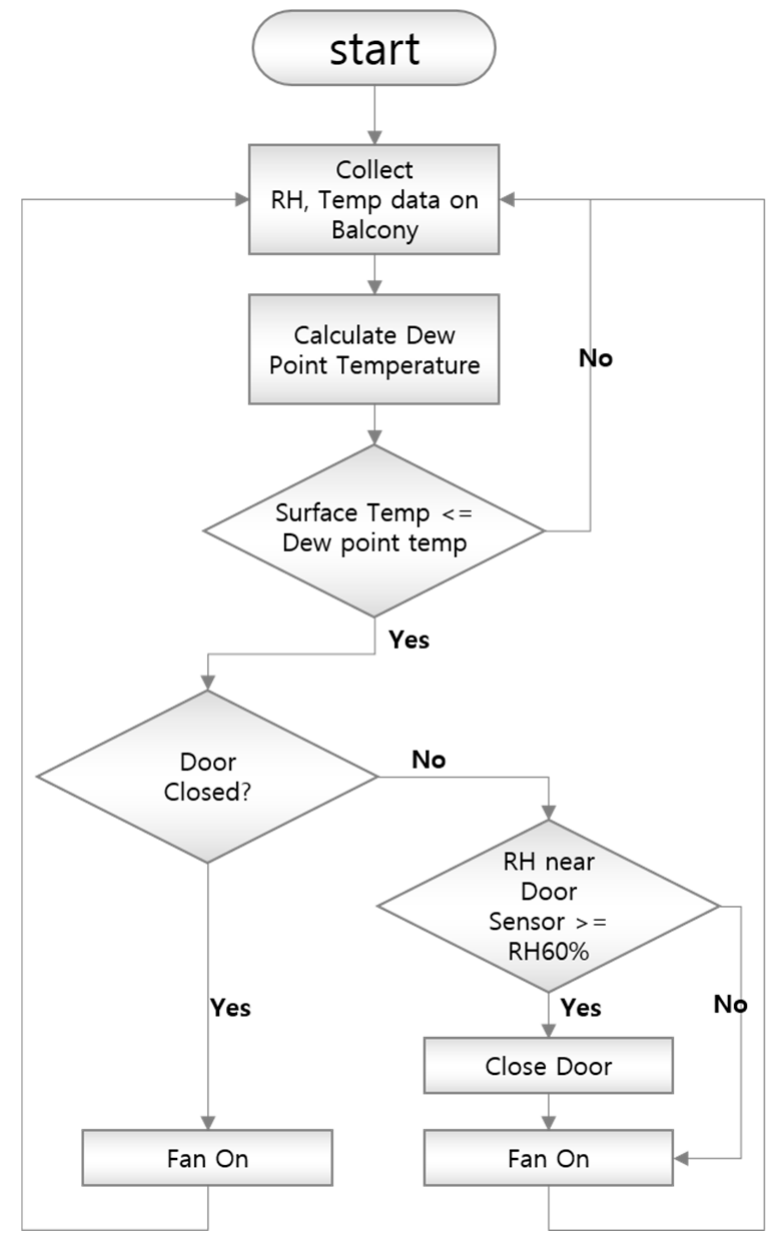

Figure 14. Condensation control algorithm
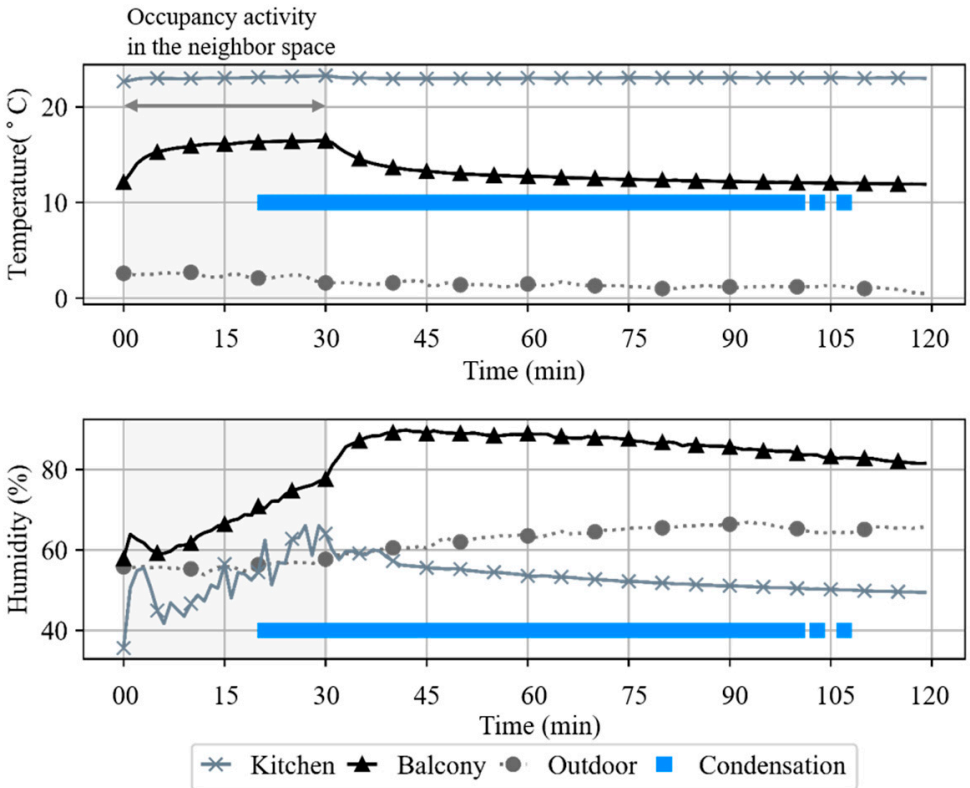

Figure 15. Moisture transfer problem with the IoT experiment. 

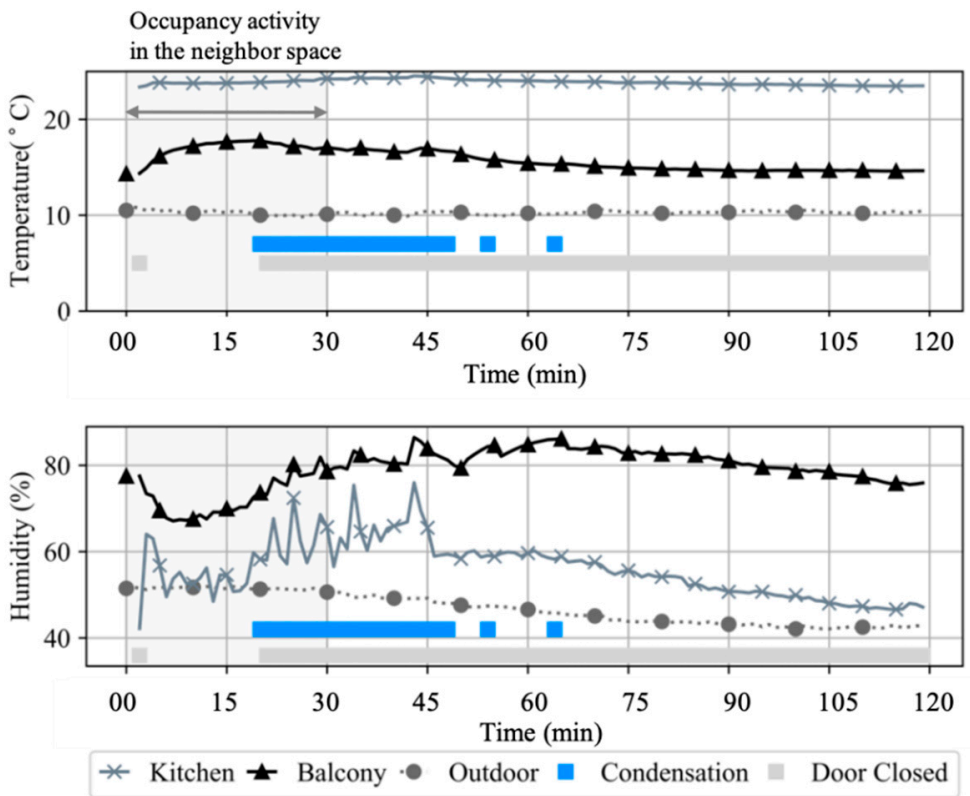

Figure 16. IoT experiment of door control according to the detection of indoor condensation.
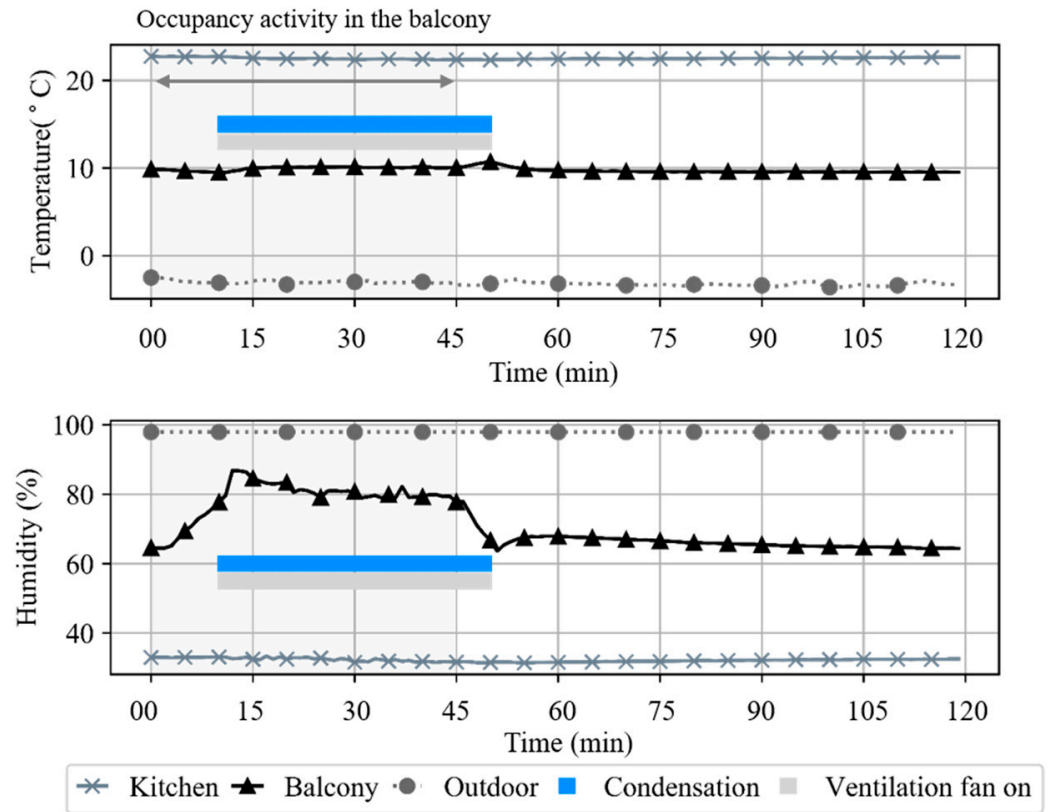

Figure 17. IoT experiment of ventilation fan operation with the detection of condensation due to the generation of moisture in the balcony.

Once the IoT environment is established, the control parameters and algorithm are implemented; the strategy of preventing or mitigating condensation varies by the user. Each control parameter object can optionally be controlled through various control algorithm combinations depending on the occupancy patterns. The door control and fan ventilation parameters can be operated together to shorten the condensation duration, as shown in Figure 18. Situations may occur in which the occupant may wish to keep the balcony door open for various reasons; thus, only the ventilation can be operated to remove transferred water vapor, as shown in Figure 19. Applying the proposed IoT strategy with a simple algorithm is effective for controlling condensation compared with a control strategy that utilizes fixed parameters. However, condensation remains for some time at the beginning since the algorithm initiates the parameter after detecting condensation. Therefore, the algorithm can 
be improved with AI techniques by trained data to control the occurrence of condensation prior to occurring. Nevertheless, to improve the algorithm, this IoT strategy must be implemented.
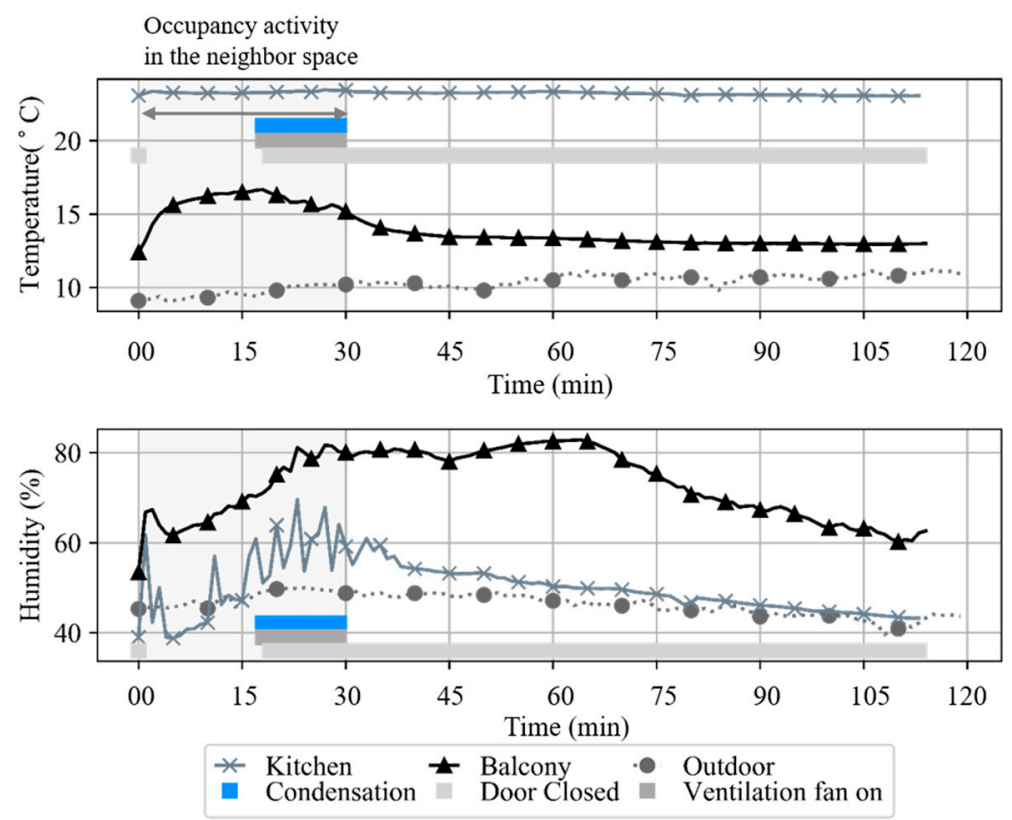

Figure 18. IoT experiment of ventilation fan and door operation while condensation is detected in the balcony.
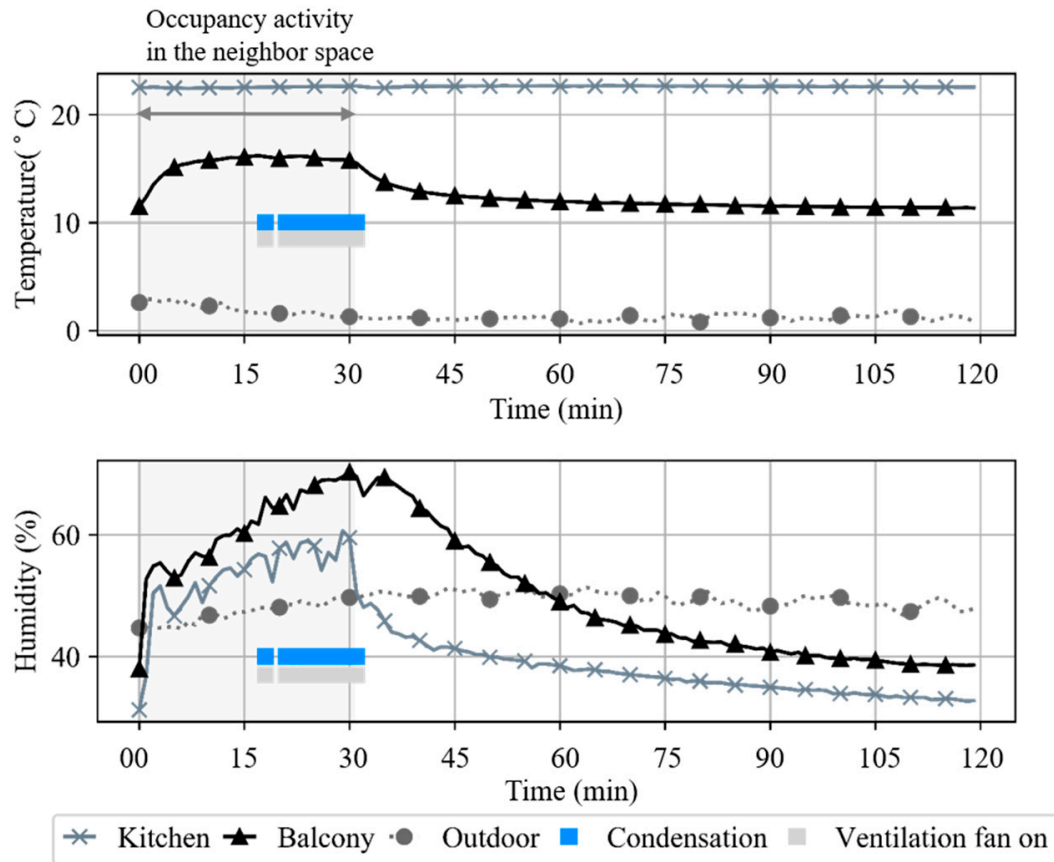

Figure 19. IoT experiment of ventilation fan operation while condensation is detected due to moisture being transferred from the kitchen.

\section{Conclusions}

This study was intended to provide a design solution to prevent condensation in Korean apartment balconies. Additionally, we investigated the limitations of the fixed parameter and the validity of occupancy parameter control strategies by using IoT applications. The balcony suffers the worst condensation problems in Korean residential units; this problem is often reported even in newly 
constructed buildings. Thus, it is necessary to identify the inadequate design conditions used in construction that repeatedly lead to such condensation problems. In this study, field measurements were first taken in a balcony space to derive the control parameters; then, the physical design values were reviewed using a simulation model to understand the limitations of fixed parameters. Finally, an IoT experimental unit was implemented to confirm the application of the design solution to the condensation problem.

Field measurements were taken to study both the condensation problem in Korean balcony spaces and the relevant control parameters. The results revealed that balcony spaces are constructed without an insulation or heating system; however, balcony spaces are influenced by the transfer of moisture from the kitchen as well as moisture generation activities within the balcony. Based on these field measurement results, we found that the transfer of moisture to this unheated space needs to be prevented by controlling the opening of the balcony door, by installing a ventilation system to transfer any generated moisture, and by applying insulation to the wall surfaces.

These condensation control strategies were reviewed using a simulation model and an on-site experiment with a real-time sensor control implemented IoT device. Fixed parameter values for insulation thickness requires similar properties as that applied in a conditioned space. However, insulation is not appropriate for spaces where relative humidity is over $70 \%$. Fixed parameters for ventilation successfully eliminate the increase of humidity to reduce condensation. However, the continuous ventilation causes the surface temperature decrease to increase the condensation risk. The real-time sensor control strategy was employed to examine both the efficacy of intermittent ventilation and door control. A sensor-controlled balcony door blocks the further transfer of moisture from the neighboring space. The intermittent ventilation removes the transferred or produced vapor to reduce the remaining condensation time.

The condensation phenomenon and its prevention strategies are well known; however, condensation still occurs due to various unpredictable reasons. This paper defines occupancy activity as one of the unpredictable sources of moisture production that causes condensation. It may not be possible to design condensation-free houses with fixed parameters due to different occupancy patterns. Therefore, rather than providing fixed or standardized design values for built environments, it is preferable to consider controlling the building environment using home automation technologies such as the IoT. Of course, the traditional approach—providing a fixed design parameter value-remains important and necessary, and such approaches require standardized guidelines or default conditions. However, beyond the default conditions, an active control methodology or algorithm needs to be applied to comprehensively solve the condensation problem.

Author Contributions: Conceptualization, J.H.L. and M.S.Y.; methodology, J.H.L., and M.S.Y.; software, J.H.L.; data curation, J.H.L.; writing —original draft preparation, J.H.L. and M.S.Y.; writing—review and editing, J.H.L. and M.S.Y.; project administration, M.S.Y. All authors have read and agreed to the published version of the manuscript.

Funding: This research was supported by a grant (20RERP-B082204-07) from the Residential Environment Research Program funded by the Ministry of Land, Infrastructure and Transport, Korean Government.

Conflicts of Interest: The authors declare no conflict of interest.

\section{References}

1. Viitanen, H.; Vinha, J.; Salminen, K.; Ojanen, T.; Peuhkuri, R.; Paajanen, L.; Lähdesmäki, K. Moisture and bio-deterioration risk of building materials and structures. J. Build. Phys. 2010, 33, 201-224. [CrossRef]

2. Hens, H. Fungal defacement in buildings: A performance related approach. HvacR Res. 1999, 5, $265-280$. [CrossRef]

3. Garrett, M.H.; Rayment, P.R.; Hooper, M.A.; Abramson, M.J.; Hooper, B.M. Indoor airborne fungal spores, house dampness and associations with environmental factors and respiratory health in children. Clin. Exp. Allergy 1998, 28, 459-467. [CrossRef] [PubMed]

4. Bush, R.K.; Portnoy, J.M.; Saxon, A.; Terr, A.I.; Wood, R.A. The medical effects of mold exposure. J. Allergy Clin. Immunol. 2006, 117, 326-333. [CrossRef] 
5. Fisk, W.J.; Lei-Gomez, Q.; Mendell, M.J. Meta-analyses of the associations of respiratory health effects with dampness and mold in homes. Indoor Air 2007, 17, 284-296. [CrossRef]

6. Jaakkola, M.; Haverinen-Shaugnessy, U.; Doewes, J.; Nevalainen, A. Indoor dampness and mold problems in homes and asthma onset in children. In Environmental Burden of Disease Associated with Inadequate Housing-A Method Guide to the Quantification of Health Effects of Selected Housing Risks in the WHO European Region; World Health Organization: Geneva, Switzerland, 2011.

7. Lin, Z.; Zhao, Z.; Xu, H.; Zhang, X.; Wang, T.; Kan, H.; Norback, D. Home Dampness Signs in Association with Asthma and Allergic Diseases in 4618 Preschool Children in Urumqi, China-The Influence of Ventilation/Cleaning Habits. PLoS ONE 2015, 10, e0134359. [CrossRef]

8. Becker, R. Effects of heating patterns on internal surface temperatures and risk of condensation. Build. Environ. 1993, 28, 333-345. [CrossRef]

9. Hamdan, M.A. Layered wall design to prevent moisture condensation on its inside surface. Energy Convers. Manag. 2002, 43, 1821-1828. [CrossRef]

10. Liu, J.; Aizawa, H.; Yoshino, H. CFD prediction of surface condensation on walls and its experimental validation. Build. Environ. 2004, 39, 905-911. [CrossRef]

11. Su, B. Prevention of Winter Mould Growth in Housing. Archit. Sci. Rev. 2006, 49, 385-390. [CrossRef]

12. Aelenei, D.; Henriques, F.M. Analysis of the condensation risk on exterior surface of building envelopes. Energy Build. 2008, 40, 1866-1871. [CrossRef]

13. Sato, N.M.N.; Shirakawa, M.A.; Loh, K.; John, V.M. Influence of thermal properties of materials in condensation and microorganism growth on building façades. In Proceedings of the 11 DBMC International Conference on Durability of Building Materials and Components, Istanbul, Turkey, 11-14 May 2008; pp. 11-14.

14. Cho, W.; Iwamoto, S.; Kato, S. Condensation risk due to variations in airtightness and thermal insulation of an office building in warm and wet climate. Energies 2016, 9, 875. [CrossRef]

15. Oh, S.M.; Park, S.H.; Joung, K.S. Study on the Improvement Plans of Condensation Defect Examples in Apartment Building. Korean J. Air Cond. Refrig. Eng. 2017, 29, 82-88.

16. Moon, H.J.; Kim, H.-Y. The relationships between the extent of mould problems and physical building characteristics in high-rise apartment buildings. In Proceedings of the Clima 2007 WellBeing Indoors, Helsinki, Finland, 10-14 June 2007; Volume 5.

17. Dictionary, M.-W. Merriam-Webster. 2002. Available online: https://www.merriam-webster.com/dictionary/ balcony (accessed on 8 August 2019).

18. Park, C. Emerging from Customary Design for Balcony Space in Apartment. J. Arch. Inst. Korea Plan 2004, 20, $67-76$.

19. Kim, S.-Y.; Oh, C.-O. A Study of Current Status and Residents' Needs of Balcony Extension in Korean Apartment Housing. Korean Inst. Inter. Des. J. 2012, 21, 152-162.

20. Enforcement Decree of the Building Act Korea. Available online: http://www.law.go.kr/법령/건축법\%20시행 령/제119조 (accessed on 1 September 2019).

21. Gutt, G. Condensation in attics: Are vapor barriers really the answer? Energy Build. 1979, 2, $251-258$. [CrossRef]

22. Janssens, A.; Hens, H. Interstitial condensation due to air leakage: A sensitivity analysis. J. Therm. Envel. Build. Sci. 2003, 27, 15-29. [CrossRef]

23. Ali, M.; Oladokun, M.O.; Osman, S.B.; Samsuddin, N.; Hamzah, H.A. Moisture condensation on building envelopes in differential ventilated spaces in the tropics: Quantitative assessment of influencing factors. MATEC Web Conf. 2016, 66, 00089. [CrossRef]

24. Moon, H.J.; Ryu, S.H.; Choi, M.S.; Kim, S.K.; Yang, S.H. Evaluation of mould growth risk in apartment houses using hygrothermal simulation. In Building Simulation; International Building Performance Simulation Association: Sydney, Australia, 2011.

25. Standard, A. Standard 160-2009: Criteria for Moisture Control Design Analysis in Buildings; American Society of Heating, Refrigerating and Air-Conditioning Engineers: Atlanta, GA, USA, 2009.

26. TenWolde, A.; Walker, I.S. Interior moisture design loads for residences. In Proceedings Thermal Performance of Exterior Envelopes of Buildings VIII; ASHRAE: Atlanta, GA, USA, 2001.

27. Yik, F.; Sat, P.; Niu, J. Moisture generation through Chinese household activities. Indoor Built Environ. 2004, 13, 115-131. [CrossRef] 
28. Zemitis, J.; Borodinecs, A.; Frolova, M. Measurements of moisture production caused by various sources. Energy Build. 2016, 127, 884-891. [CrossRef]

29. Gubbi, J.; Buyya, R.; Marusic, S.; Palaniswami, M. Internet of Things (IoT): A vision, architectural elements, and future directions. Future Gener. Comput. Syst. 2013, 29, 1645-1660. [CrossRef]

30. Moreno, M.; Úbeda, B.; Skarmeta, A.; Zamora, M. How can we tackle energy efficiency in iot basedsmart buildings? Sensors 2014, 14, 9582-9614. [CrossRef] [PubMed]

31. Bashir, M.R.; Gill, A.Q. Towards an IoT big data analytics framework: Smart buildings systems. In Proceedings of the 2016 IEEE 18th International Conference on High Performance Computing and Communications; IEEE 14th International Conference on Smart City; IEEE 2nd International Conference on Data Science and Systems (HPCC/SmartCity/DSS), Sydney, Australia, 12-14 December 2016; pp. 1325-1332.

32. Pocero, L.; Amaxilatis, D.; Mylonas, G.; Chatzigiannakis, I. Open source IoT meter devices for smart and energy-efficient school buildings. HardwareX 2017, 1, 54-67. [CrossRef]

33. Tang, S.; Kalavally, V.; Ng, K.Y.; Parkkinen, J. Development of a prototype smart home intelligent lighting control architecture using sensors onboard a mobile computing system. Energy Build. 2017, 138, 368-376. [CrossRef]

34. Plus, E. Energy Plus Engineering Reference. In Building Technologies Program; US Department of Energy: Washington, DC, USA, 2013.

35. Riffat, S. A study of heat and mass transfer through a doorway in a traditionally built house. Ashrae Trans $1989,95,584-589$.

(C) 2020 by the authors. Licensee MDPI, Basel, Switzerland. This article is an open access article distributed under the terms and conditions of the Creative Commons Attribution (CC BY) license (http://creativecommons.org/licenses/by/4.0/). 